CZASOPISMO INŻYNIERII LĄDOWEJ, ŚRODOWISKA I ARCHITEKTURY JOURNAL OF CIVIL ENGINEERING, ENVIRONMENT AND ARCHITECTURE

JCEEA, t. XXXIII, z. 63 (3/16), lipiec-wrzesień 2016, s. 553-562

Robert ZARZYCKI ${ }^{1}$

Zbigniew BIS ${ }^{2}$

\title{
ZASTOSOWANIE PALENISKA CYKLONOWEGO W PROCESIE WITRYFIKACJI POPIOLÓW LOTNYCH NA POTRZEBY PRODUKCJI MATERIALÓW BUDOWLANYCH
}

\begin{abstract}
W artykule przedstawiono możliwości wykorzystania paleniska cyklonowego w procesie witryfikacji popiołów lotnych na potrzeby produkcji materiałów budowlanych. Proponowane rozwiązanie oprócz funkcji topienia popiołów lotnych i przygotowania na ich bazie materiałów o wymaganych właściwościach pozwala na zabudowę w układzie kotła bloku parowego. Dzięki temu palenisko cyklonowe zwiększa elastyczność energetyczną kotła a tym samym całego bloku parowego. Poprzez jego zabudowę możliwe jest w okresie "doliny nocnej" wyłączenie podstawowych palników kotła pyłowego, jednocześnie utrzymując go w stanie gorącej rezerwy dzięki spalaniu gazów powstałych w procesie spalania i zgazowania pyłu węglowego w palenisku cyklonowym. Dzięki takiemu rozwiązaniu możliwe jest znaczące obniżenie kosztów utrzymania bloku parowego w gotowości do produkcji energii elektrycznej przy jednoczesnym przetwarzaniu popiołów lotnych do użytecznych gospodarczo materiałów. Z punktu widzenia procesu witryfikacji popiołu lotnego korzystne jest stosowanie popiołów lotnych o wysokiej stracie prażenia. Uzyskany w trakcie procesu witryfikacji produkt charakteryzuje się stratą prażenia na poziomie $0.1 \%$. Poprzez zastosowanie odpowiedniego procesu chłodzenia płynnego żużla możliwe jest uzyskanie materiału o dużej porowatości który można wykorzystać np. przy produkcji pustaków ściennych.
\end{abstract}

Słowa kluczowe: zeszkliwienie, topienie, kruszywa, oxy-spalanie, kocioł pyłowy

\section{Wprowadzenie}

Bezpieczeństwo energetyczne to nie tylko zapewnienie niezakłóconego zaopatrywania odbiorców w energię elektryczną, utrzymanie niskich kosztów jej wytwarzania, lecz także wypełnienie zobowiązań środowiskowych nie tylko w zakresie ograniczenia emisji zanieczyszczeń gazowych, ale także ograniczenia

${ }^{1}$ Autor do korespondencji: Robert Zarzycki, Politechnika Częstochowska, Katedra Inżynierii Energii, ul. Brzeźnicka 60a, 42-200 Częstochowa; tel. 343250902, 343257334 wew. 18; zarzycki@is.pcz.czest.pl

${ }^{2}$ Zbigniew Bis, Politechnika Częstochowska, Katedra Inżynierii Energii, ul. Brzeźnicka 60a, 42-200 Częstochowa; tel. 343257334 wew. 18; zbis@is.pcz.czest.pl 
składowania Ubocznych Produktów Spalania (UPS) (popiołów, żużli). Powstające w procesie spalania popioły oraz żużle często zanieczyszczone są niewykorzystanymi pozostałościami sorbentów (np. $\mathrm{CaSO}_{3}, \mathrm{CaSO}_{4}, \mathrm{CaO}$, amoniak, węgiel aktywny itp.). Dyrektywy Unii Europejskiej (UE) zobowiązują kraje członkowskie do zwiększenia stopnia gospodarczego wykorzystania (recykling) odpadów powstających w procesach produkcji. Oprócz tych, standardowych już dziś, wymagań pojawiają się nowe, będące następstwem sukcesywnego wdrażania polityki klimatycznej. Wprowadzanie w następstwie tych procesów coraz większej mocy wytwarzanej z Odnawialnych Źródłach Energii (OZE), które objęte są priorytetem obowiązkowego odkupienia od wytwórców, powoduje „wypieranie” energetyki węglowej z tzw. ,podstawy” w rejon ,podszczytowy”, który cechuje się zmiennym w ciągu doby zapotrzebowaniem na wytwarzany prąd. Dalszy wzrost udziału OZE prowadzić będzie do pogłębienia tego stanu z koniecznością wyłączania bloków węglowych w okresie nocy, by ponownie uruchamiać je w porze dnia, lub okresach bezwietrznych lub dużego zachmurzenia. Bloki z kotłami opalanymi pyłem węgla kamiennego lub brunatnego aktualnie pracujące w Krajowym Systemie Energetycznym (KSE), nie są przystosowane do takiej elastyczności, wobec czego w najbliższej perspektywie winny być poddane stosownym modyfikacjom.

Wobec powyższego w przypadku polskiego KSE, który w dużym stopniu oparty jest o spalanie paliw kopalnych sektor energetyczny staje przed nie lada wyzwaniami, szczególnie gdy węgle dobrej jakości (m.in. o niskiej zawartości popiołu) w znacznym stopniu zostały już wydobyte i spalone. W Polsce znacząca ilość UPS wykorzystywana jest do produkcji materiałów budowlanych [1,2,3,4] lub jako materiał podsadzkowy dla wypełniania wyrobisk w kopalniach. Wykorzystanie popiołów lotnych do produkcji materiałów budowlanych wymaga jednak spełnienia szeregu wymagań, zwłaszcza dotyczących zawartości węgla (m.in. straty prażenia), zapisanych w normach PN-EN 450-1:2012, PN-EN 206:2014-04.

W niniejszej pracy przedstawiono propozycję urządzenia, które współpracując z kotłem energetycznym bloku parowego opalanego węglem kamiennym lub brunatnym czyni zadość co najmniej dwu w/w ważnym wyzwaniom. Ułatwia zwiększenie jego elastyczności poprzez obniżenie minimum technicznego do poziomu co najmniej 20\% maksymalnej wydajności (szczególnie w czasie "doliny nocnej") jednocześnie realizując przetwarzanie popiołu lotnego o właściwościach nie pozwalających na jego bezpośrednie wykorzystanie w produkcji materiałów budowlanych na produkt $w$ postaci kruszyw lekkich lub materiałów zeszkliwionych, spełniające wymagania stawiane materiałom budowlanym.

\section{System elektroenergetyczny}

Produkcja energii elektrycznej związana jest bezpośrednio z jej zużywaniem przez jej odbiorców. W chwili obecnej brak technicznych możliwości jej magazynowania na potrzeby KSE. Z tego też względu elektrownie węglowe w ciągu dnia muszą być przygotowane do zapewnienia dostaw energii elektrycznej $\mathrm{w}$ ilości 
wymaganej w danej chwili przez odbiorców, natomiast w czasie "doliny nocnej", gdzie zapotrzebowanie na energię elektryczną spada, pojawia się konieczność pracy z mocą minimalną. $\mathrm{W}$ wielu przypadkach wymagana moc przez system elektroenergetyczny jest niższa od sumy minimalnych mocy pracujących aktualnie bloków energetycznych, co stwarza konieczność ich czasowego wyłączenia na kilka, kilkanaście lub kilkadziesiąt godzin (w okresie weekendów i świąt). Wyłączenie bloku energetycznego wynika $\mathrm{z}$ tego, że poniżej minimum technicznego kotła proces spalania paliwa jest niestabilny szczególnie w przypadku kotłów pyłowych co zagraża bezpieczeństwu pracy kotła i obsługi technicznej. Stosowanie palników rozpałkowych opalanych gazem lub olejem opałowym lekkim w czasie utrzymywania kotła w stanie gorącej rezerwy czy też przy ponownym rozruchu, generuje wysokie koszty eksploatacji bloku. Rozwiązaniem tego problemu może być zastosowanie paleniska cyklonowego lub zespołu palenisk cyklonowych do utrzymania kotła w stanie gorącej rezerwy w czasie "doliny nocnej". Proponowane palenisko cyklonowe oprócz funkcji energetycznej służyć może także jako urządzenie to przetwarzania popiołów lotnych w efekcie ich spiekania lub topienia na żużel o pożądanych własnościach fizykochemicznych i mechanicznych. Taki sposób przetwarzania można zastosować dla wykorzystania (utylizacji) popiołów lotnych, które ze względu na swój skład chemiczny (np. zawartość węgla i/lub substancji wykorzystywanych do absorpcji zanieczyszczeń gazowych) nie mogą zostać bezpośrednio wykorzystane do produkcji materiałów budowlanych.

\section{Palenisko cyklonowe}

Paleniska cyklonowe to urządzenia energetyczne, gdzie w silnie zawirowanym przepływie strumienia gazów unoszących ziarna rozdrobnionego paliwa stałego, kropli paliw ciekłych, czy też mieszaniny powietrza i paliwa gazowego realizowane są jednocześnie procesy fizyczne i chemiczne. Poprzez odpowiednie organizowanie procesu możliwe jest nie tylko prowadzenie procesu spalania lecz także zgazowania paliw stałych $[5,6,7,8,9,10,11,12,13,14]$. Palenisko cyklonowe, prezentowane w niniejszej pracy (rys. 1) składa się z dwóch części: komory dolnej PC1 i komory górnej PC2. Do komory PC2 podawane jest paliwo w postaci pyłu węglowego w strumieniu recyrkulowanych spalin lub przegrzanej pary wodnej. W komorze tej następuje jego nagrzewanie, suszenie i odgazowanie. Odgazowane paliwo przepływa grawitacyjnie do komory PC1 gdzie za pomocą zestawu dysz rozmieszczonych wzdłuż jej wysokości podawany jest gaz "napędowy", którego zadaniem w pierwszej kolejności jest utrzymanie przepływu zawirowanego odgazowanego paliwa oraz stworzenie odpowiednich warunków procesowych pozwalających na jego spalanie lub zgazowanie. Dysze napędowe umieszczone są stycznie to tworzącej walcowej komory PC1. Szczegóły konstrukcyjne budowy paleniska cyklonowego przedstawiono w pracach $[11,12,13,14,15,16,17]$. 

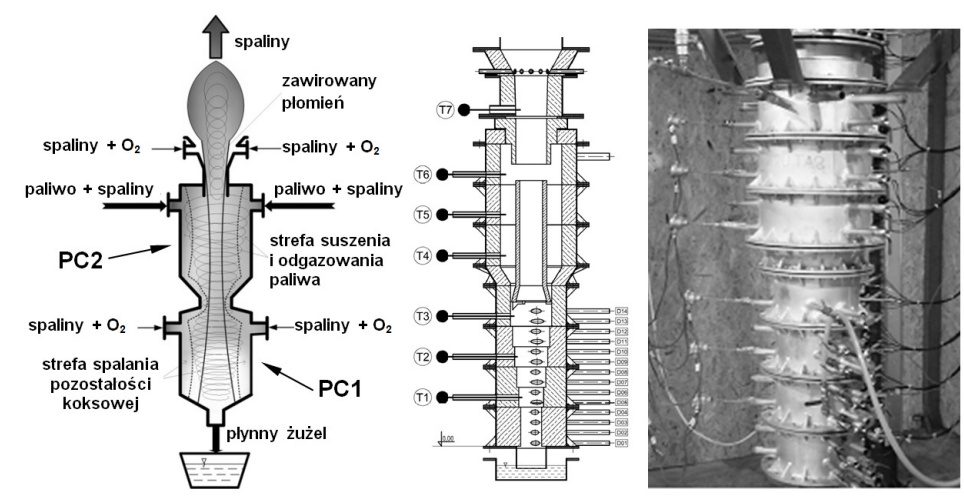

Rys. 1. Schemat oraz widok paleniska cyklonowego

Fig. 1. Schematics and view of the cyclone furnace

W palenisku tym może być prowadzony klasyczny proces spalania paliwa w powietrzu, jak również możliwa jest realizacja procesu w atmosferze wzbogaconej w tlen tzw. oxy-spalanie $[18,19]$. Ponieważ w paleniskach cyklonowych proces spalania przebiega $\mathrm{w}$ wysokich temperaturach [17], przekraczających $1200 \div 1600^{\circ} \mathrm{C}$, zasilanie powietrzem przyczynia się do wysokiej emisji tlenków azotu, realizacja w tych warunkach oxy-spalania eliminuje w dużym stopniu ten problem a także pozwala na uzyskiwanie wyższych temperatur prowadzenia procesu. Realizacja procesu oxy-spalania pozwala także na łatwiejsze ograniczenie emisji dwutlenku węgla do atmosfery dzięki temu, że spaliny zawierające duże stężenie $\mathrm{CO}_{2}$ mogą być bezpośrednio wykorzystywane w przemyśle chemicznym, rolnictwie bądź składowane pod ziemią (CCS) [19]. W Katedrze Inżynierii Energii Politechniki Częstochowskiej w ramach Strategicznego Programu „ZAAWANSOWANE TECHNOLOGIE POZYSKIWANIA ENERGII” zostały przeprowadzone obszerne badania procesu spalania i zgazowania pyłu węglowego w opisanym wyżej palenisku cyklonowym. Potwierdziły one założenia dotyczące możliwości prowadzenia procesu spalania i zgazowania pyłu węglowego w warunkach podwyższonego stężenia tlenu $[7,9,10,11,12,13]$. Otrzymane wyniki pokazały możliwość uzyskania w centralnej części komory PC1 temperatury przekraczającej poziom $1400^{\circ} \mathrm{C}[6,11,12,13]$. Podobne wyniki osiągnięto także realizując obliczenia numeryczne przebiegu procesu spalania i zgazowania paliwa $\mathrm{w}$ analizowanych warunkach $[5,7,9,10]$. Obliczenia te wykazały także, że prowadząc proces spalania i zgazowania paliwa $\mathrm{w}$ atmosferze tlenowej oraz w obecności pary wodnej możliwe jest uzyskiwanie w komorze PC1 temperatur dochodzących do $1700^{\circ} \mathrm{C}$ przy jednoczesnej produkcji gazów palnych zawierających głównie CO oraz $\mathrm{H}_{2}$. Gazy te, których wartość opałowa dochodzi do $12 \mathrm{MJ} / \mathrm{kg}$ można spalić w komorze kotła pyłowego np. w celu utrzymania go w gorącej rezerwie w okresie pracy z niskim obciążeniem lub ze względu na wysoką zawartość wodoru dochodzącą do $50 \%$ wykorzystać w procesach chemicznych. 
Omówione powyżej warunki panujące w komorze PC1 stwarzają potencjalne możliwości realizacji tam procesu witryfikacji popiołu lotnego, osadów ściekowych lub innych substancji w celu ich neutralizacji. Uzyskane produkty mogą zostać wykorzystane jako surowce przy produkcji materiałów budowlanych.

\section{Witryfikacja popiołów lotnych}

Witryfikacja jest procesem termicznym polegającym na kontrolowanym dostarczaniu ciepła [20] do witryfikowanej substancji w celu usunięcia z niej gazów oraz substancji palnej (np. węgiel) a następnie stopieniu pozostałej substancji mineralnej. Powstała faza ciekła poddana procesowi kontrolowanego chłodzenia pozwala na uzyskanie materiału o pożądanych właściwościach i strukturze np. zbliżonej do szkła, lub materiału o dużej porowatości. Źródłem ciepła w procesie witryfikacji może być energia elektryczna (metoda grzania oporowego, metody plazmowe) lub ciepło uzyskane w procesie spalania paliwa (piece obrotowe, paleniska cyklonowe) $[21,22,23]$, rozważane są także metody witryfikacji z wykorzystaniem głowic mikrofalowych. Sam proces zmiany fazy (topienia) substancji popiołów wymaga dostarczenia energii w ilości około $2 \mathrm{MJ} / \mathrm{kg}$ [20,21]. W przypadku metod plazmowych i łukowych praktyczne zapotrzebowanie energii na wytryfikacje substancji mineralnych określono w zakresie 3.6-18MJ/kg [22]. Realizacja procesu witryfikacji z wykorzystaniem energii elektrycznej ze względu na koszty, może być stosowana w mniejszej skali, natomiast wykorzystanie energii chemicznej paliwa w procesie witryfikacji oraz do zasilania np. kotła pyłowego gorącymi, palnymi gazami pozwala na bardziej efektywne wykorzystanie energii oraz znaczące obniżenie jednostkowych kosztów procesu.

Do witryfikacji w palenisku cyklonowym wykorzystywane powinny być przede wszystkim popioły, które nie spełniają norm ze względu na wysoką zawartość węgla (wysoka strata prażenia). Zastosowanie takich popiołów może ograniczyć zapotrzebowanie na paliwo do utrzymania warunków wymaganych do realizacji procesu witryfikacji tym samym obniżyć koszty tego procesu.

Popioły lotne powstające w wyniku spalenia węgla kamiennego i brunatnego, są wychwytywane poza kotłem ze spalin najczęściej z wykorzystaniem odpylaczy cyklonowych, filtrów workowych lub elektrofiltrów. Skład popiołów lotnych uzależniony jest w dużej mierze od składu substancji mineralnej zawartej w węglu, rodzaju paleniska (pyłowe, fluidalne) oraz warunków prowadzenia procesu (temperatura, stopień rozdrobnienia paliwa, sposób odsiarczania) który wpływa w dużym stopniu na zawartość węgla w popiele lotnym.

Podstawowymi składnikami pyłów są krzemionka $\left(\mathrm{SiO}_{2}\right)$, związki glinu (np. $\mathrm{Al}_{2} \mathrm{O}_{3}$ ), związki żelaza (np. $\mathrm{Fe}_{2} \mathrm{O}_{3}$ ), związki wapnia $(\mathrm{CaO})$, związki magnezu $(\mathrm{MgO})$ [1]. Temperatury topnienia czystych tlenków wchodzących w skład popiołu mieszczą się w zakresie od 800 do $2800^{\circ} \mathrm{C}$ [1], jednak już mieszaniny eutektyczne tych tlenków posiadają temperatury wyraźnie niższe dochodzące do 1200$1800^{\circ} \mathrm{C}$. Temperaturę topnienia można obniżać poprzez dodatek topników w po- 
staci $\mathrm{CaO}$ czy $\mathrm{FeO}$ [1]. W wielu przypadkach w składzie lotnych popiołów $\mathrm{CaO}$ występuje w naturalnej formie lub jako niewykorzystana część sorbentów wapniowych, dodawanych w celu redukcji emisji siarki. Dzięki zastosowaniu dodatku topników oraz kontroli temperatury wewnątrz paleniska możliwa jest kontrola procesu witryfikacji od pełnego przetopienia popiołu do stopienia jedynie jego części co pozwoli na uzyskanie materiałów o porowatej strukturze.

Na rys. 2a pokazano przebieg procesu spalania pyłu węglowego w omawianym palenisku cyklonowym w komorze PC1. Wyraźnie widoczny jest przepływ zawirowany ze spalaniem poruszających się intensywnie ziaren paliwa. Wprowadzenie pneumatycznie popiołu lotnego do tak zawirowanego strumienia wyniku podania za pomocą dyszy "napędowej" (rys. 2b) powoduje praktyczne natychmiastowy proces jego topienia w wyniku czego na ściankach wewnętrznych powstaje warstwa płynnego żużla. Żużel ten gromadząc się na stopniach komory PC1 ulega wygrzewaniu i ujednorodnianiu (jasne okręgi - rys. 2c) po czym zaczyna spływać do wanny żużlowej znajdującej sie poniżej komory PC1 (rys. 2d).

$\mathrm{Na}$ rysunku 3 przedstawiono widok wnętrza komory PC1 po zakończonym procesie topienia popiołu lotnego. Widoczne jest pokrycie wnętrza komory warstwą zastygłego żużla (rys. 3 a i b). Taka sytuacja jest korzystna ze względu na ochronę wnętrza przed erozją wywołaną kontaktem ziaren pyłu węglowego oraz popiołu lotnego z materiałem stanowiącym wyłożenie ceramiczne komory. $\mathrm{Na}$ rysunku 3c widoczny jest powstały w procesie topienia żużel w dolnej części komory uzyskany $\mathrm{w}$ wyniku chłodzenia gazem "napędowym" z dużą prędkością. W tym przypadku możliwe jest uzyskanie żużla o dużej porowatości (rys. 4).
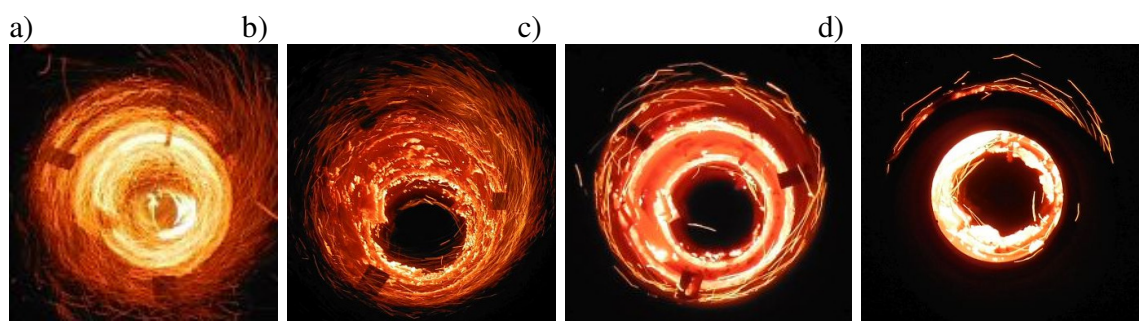

Rys. 2. Widok wnętrza komory PC1 podczas spalania pyłu węglowego pokrytej płynnym żużlem

Fig. 2. View of the interior chamber PC1 during the combustion of coal dust coated with molten slag

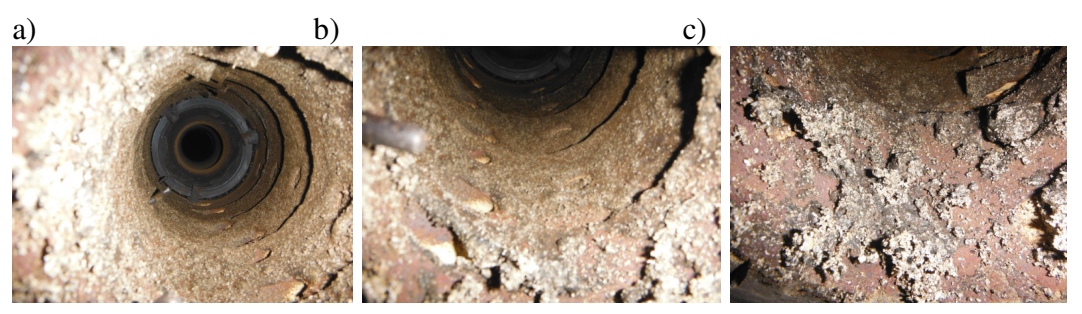

Rys. 3. Widok wnętrza komory PC1 pokrytej żużlem

Fig. 3. View of the interior chamber PC1 covered with slag 

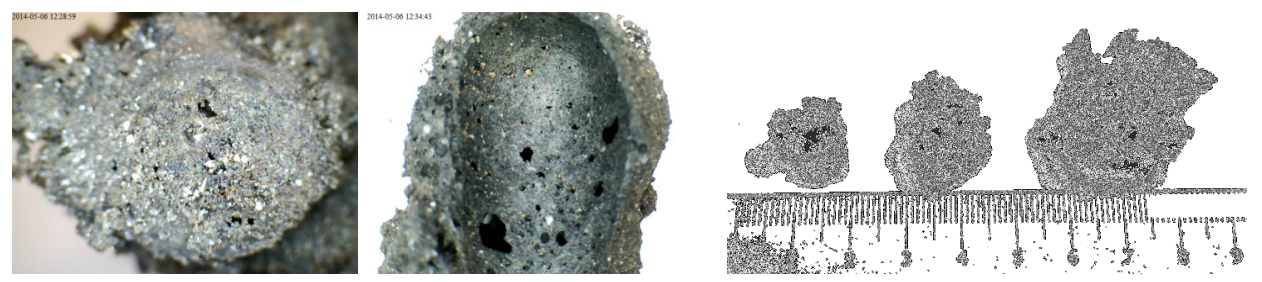

Rys. 4. Widok materiału uzyskanego podczas procesu witryfikacji popiołu lotnego

Fig. 4. View of the material obtained during the process of vitrification of fly ash

Przeprowadzone badania procesu witryfikacji z wykorzystaniem paleniska cyklonowego pozwoliły, w zależności od warunków prowadzenia procesu, uzyskać żużel o stracie prażenia poniżej $0.1 \%$.

Procesowi witryfikacji oprócz popiołów lotnych podane mogą być odpady powstające w takich gałęziach przemysłu jak: odlewnictwo metali żelaznych i nieżelaznych, przemysł naftowy, chemiczny, elektroniczny a zwłaszcza energetyczny [24]. Poddane procesowi witryfikacji odpady z wymienionych powyżej gałęzi gospodarki charakteryzują się wysoką odpornością na wymywanie składników toksycznych, dużą trwałością, odpornością na czynniki środowiskowe jak i atmosferyczne $[24,25,26]$. Produkty witryfikacji posiadają właściwości porównywalne do powszechnie stosowanych kruszyw mineralnych i sztucznych stosowanych w budownictwie na podbudowy drogowe [24]. Zeszklone popioły nadają się do szerokiego stosowania w budownictwie do produkcji lekkich betonów i zapraw ciepłochronnych, do wyrobu pustaków ściennych i stropowych, a także do stabilizacji gruntów i drenaży wodnych w geotechnice [24].

\section{Proces spalania i zgazowania paliwa oraz topienia popiołów lotnych w palenisku cyklonowym}

Przeprowadzone badania procesu spalania i zgazowania pyłu węglowego w palenisku cyklonowym, nie tylko potwierdziły możliwość elastycznej realizacji obu procesów, lecz także pokazały możliwość jednoczesnej realizacji tych procesów w połączeniu z topieniem osobno wprowadzanego popiołu lotnego w celu jego stopienia (witryfikacji) [5,6,7,8,9,10,11,12,13]. W takim przypadku paliwo (pył węglowy) podawane jest do komory PC2 gdzie następuje proces jego nagrzewania, suszenia i odgazowania, pozostałość koksowa dopalana jest w komorze $\mathrm{PC} 1$ powodując wzrost temperatury do poziomu $1400-1500^{\circ} \mathrm{C}$. Po osiągnięciu tego stanu do komory PC1 może być rozpoczęte pneumatyczne podawanie lotnego popiołu w strumieniu gazu "napędowego" zawierającego utleniacz. W wyniku jego zawirowania i wysokiej temperatury ulega on szybkiemu nagrzaniu i stopieniu. Stopiony popiół w postaci płynnej spływa po ścianach komory PC1 do wanny żużlowej gdzie ulega ochłodzeniu. Dzięki zabudowie dysz doprowadzających gaz "napędowy" w dolnej części paleniska możliwe jest stopniowe 
chłodzenie płynnego żużla, jednocześnie tworząc strukturę żużla o dużej porowatości. Dzięki zabudowie w tej strefie elementu obrotowego pozwalającego na zgarnianie i kruszenie żużla można uniknąć problemów z jego niezakłóconym wyprowadzaniem z dolnej części paleniska cyklonowego. Sposób chłodzenia płynnego żużla ma znaczący wpływ na właściwości i strukturę uzyskiwanego produktu. Palenisko opuszcza mieszanina gazów palnych (części lotnych, $\mathrm{CO}, \mathrm{H}_{2}$ ) oraz spalin o wysokiej temperaturze. W komorze kotła pyłowego następuje dopalenie części lotnych i przekazanie ciepła fizycznego zawartego w tych gazach.

Opisana powyżej propozycja pracy paleniska cyklonowego może być realizowana zarówno przy maksymalnej wydajności kotła, jak również, co szczególnie ważne, przy znacznie obniżonej wydajności, zapewniając stabilne utrzymanie znacznie obniżonego minimum technicznego. W tym przypadku w zależności od mocy i liczby palenisk cyklonowych zabudowanych w układzie kotła pyłowego możliwe jest wyłączenie pewnej części palników pyłowych i stabilizacja ich pracy poprzez dopalanie gazów generowanych przez palenisko cyklonowe. Można rozważyć także całkowite wyłączenie palników pyłowych i utrzymywanie kotła w gorącej rezerwie dzięki proponowanemu rozwiązaniu. W tym przypadku w czasie tzw. "doliny nocnej" możliwa jest realizacja procesu witryfikacji popiołu na potrzeby produkcji materiałów budowlanych.

\section{Podsumowanie}

Przedstawione w niniejszej pracy palenisko cyklonowe wykorzystane może być zarówno w celach energetycznych jak i w procesie witryfikacji popiołów lotnych. Palenisko cyklonowe zasilane pyłem węglowym pozwala na jego częściowe spalanie oraz zgazowanie. Uzyskane gazy palne mogą zostać spalone w komorze kotła pyłowego, a ciepło uzyskane z częściowego spalania pyłu węglowego wykorzystane do topienia popiołu lotnego. Dzięki takiej realizacji procesu możliwe jest znaczące obniżenie nakładów energetycznych na realizacje procesu wykorzystując dodatkowo węgiel oraz topniki zawarte w przetwarzanym popiele lotnym. Zastosowanie odpowiedniego sposobu chłodzenia płynnego żużla pozwala na otrzymanie kruszyw o różnych właściwościach od bardzo porowatych do kruszyw o bardzo zwartej strukturze.

Podziękowania BS/PB-404-301/11

\section{Literatura}

[1] Kołakowski J., Szymański E.: Popioły paleniskowe w budownictwie, Wydawnictwo Arkady, Warszawa 1961.

[2] Reiss H., Kiersztyn E.: Żużel i tworzywa żużlowe w budownictwie, Wydawnictwo Arkady, Warszawa 1960.

[3] Galos K., Uliasz-Bocheńczyk A.: Źródła i użytkowanie popiołów lotnych ze spalania węgli w Polsce, Gospodarka Surowcami Mineralnymi, tom 21, zeszyt 1, 2005, s. 23-42. 
[4] Stefańczyk B. praca zbiorowa: Budownictwo ogólne Tom 1 Materiały i wyroby budowlane, Wydawnictwo Arkady, 2005.

[5] Zarzycki R., Warzecha P., Kobyłecki R., Bis Z., Modelowanie matematyczne i symulacje numeryczne tlenowego spalania węgla oraz zgazowania w przedpalenisku cyklonowym, Spalanie tlenowe dla kotłów pyłowych i fluidalnych zintegrowanych z wychwytem $\mathrm{CO} 2$, seria Monografie nr 301, Częstochowa 2015, pp. 310 - 334.

[6] Kobyłecki R., Zarzycki R., Bis Z.: Przedpalenisko cyklonowe dla spalania i zgazowania pyłu węglowego, Wydawnictwo ITC, Energetyka Gazowa tom 2, 2016, s. 277-285.

[7] Zarzycki R., Bis Z.: Modelowanie procesu spalania i zgazowania pyłu węglowego w palenisku cyklonowym, Wydawnictwo ITC, Energetyka Gazowa tom 2, 2016, s. 361-376.

[8] Zarzycki R., Bis Z., Kobyłecki R.: The concept of coal burning in a cyclone furnace, IX ICCHME, 23-26 May 2016, Cracow, Poland, no. 492.

[9] Zarzycki R., Bis Z.: Modelling of the process of coal dust combustion in a cyclone furnace, IX ICCHME, 23-26 May 2016, Cracow, Poland, no. 493.

[10] Zarzycki R., Bis Z.: Modelling of coal dust gasification in a cyclone furnace under oxyfuel combustion conditions, IX ICCHME, 23-26 May 2016, Cracow, Poland, no. 494.

[11] Zarzycki R., Kratofil M., Pawłowski D., Ścisłowska M., Kobyłecki R., Bis Z., Analiza spalania pyłu węglowego w przedpalenisku cyklonowym, Polityka Energetyczna, t. 16, zeszyt 3, 2013, s. 325-337.

[12] Zarzycki R., Kobyłecki R., Kratofil M., Ścisłowska M., Pawłowski D., Bis Z., Badania spalania pyłu węglowego w przedpalenisku cyklonowym, Polityka Energetyczna tom 17, z. 3. Wyd. Instytutu GSMiE PAN, Kraków, s. 381 - 392.

[13] Kobyłecki R., Zarzycki R., Kratofil M., Pawłowski D., Bis Z., Badania spalania pyłu węglowego w przedpalenisku cyklonowym, Aktualne Zagadnienia Energetyki, TOM I, Oficyna Wydawnicza Politechniki Wrocławskiej, Wrocław, 2014.

[14] Bis Z., Kobyłecki R., Zarzycki R., Urządzenie do spalania i zgazowania paliw stałych, Zgłoszenie wynalazku P.411668, 2015.

[15] Zarzycki R., Kratofil M., Pawłowski D., Ścisłowska M., Kobyłecki R., Bis Z., Analiza wyników obliczeń numerycznych przepływu pyłu węglowego oraz gazu w palenisku cyklonowym, Polityka Energetyczna, t. 16, zeszyt 3, 2013, s. 301-312.

[16] Zarzycki R., Kratofil M., Pawłowski D., Ścisłowska M., Kobyłecki R., Bis Z., Układ podawania paliwa do przedpaleniska cyklonowego, Polityka Energetyczna, t. 16, zeszyt 3, 2013, s. 313-324.

[17] Zarzycki R., Kobyłecki R., Kratofil M., Bis Z., Kierunki rozwoju palenisk cyklonowych, Polityka Energetyczna tom 17, z. 4. 2014. Wyd. Instytutu GSMiE PAN, Kraków, s. $249-261$.

[18] Nowak W., Pronobis M.: Nowe technologie spalania i oczyszczania spalin. Wydawnictwo Politechniki Śląskiej, 2010, Gliwice.

[19] Nowak W., Czakiert T.: Spalanie tlenowe dla kotłów pyłowych i fluidalnych zintegrowanych z wychwytywaniem CO2. Wydawnictwo Politechniki Częstochowskiej, 2012, Częstochowa.

[20] Kordylewski W., Robak Ł.: Witryfikacja odpadów i popiołów, Gospodarka Paliwami i Energią, nr 7, 2002, s. 18-21.

[21] http://www.spalanie.pwr.wroc.pl/badania/publikacje/witryfikacja.PDF \{dostęp 2016.05.16\}. 
[22] Huczko A., Lange H., Chojecki G., Dziadko D.: Plazmowa witryfikacja odpadów o charakterze pylistym, Przemysł Chemiczny, Wydawnictwo SIGMA-NOT, T. 79, nr 10, 2000, s. 333 - 335.

[23] http://www.spalanie.pwr.wroc.pl/badania/publikacje/modyfikacja\%20popiolu.pdf \{dostęp 2016.05.16\}.

[24] Borowski G., Szulżyk-Cieplak J.: Zeszkliwienie jako sposób neutralizacji odpadów niebezpiecznych, Inżynieria bezpieczeństwa a zagrożenia cywilizacyjne: zmienność zagrożeń a innowacje w ratownictwie, Centralna Szkoła Państwowej Straży Pożarnej w Częstochowie, 2014, s. 19-34.

[25] Borowski G.: Ocena przydatności zeszkliwienia osadów ściekowych do ich zagospodarowania, Ochrona środowiska i zasobów naturalnych, nr 51, 2012, s. 78-84.

[26] Kasprzyk K., Zboromirska-Wnukiewicz B., Dyjakon A., Kogut K., Kasprzyk Z.: Thermal Transformation of Combustion Wastes from Coal-Fired Boilers, Archives of Metallurgy and Materials, vol. 54, iss. 4, 2009, pp. 1021-1027.

\title{
APPLICATION PROCESS CYCLONE BURNER VITRIFICATION FLY ASH FOR THE PRODUCTION OF BUILDING MATERIALS
}

\begin{abstract}
S u m m a r y
The article presents the possibilities of using cyclone furnace in the process of vitrification of fly ash for the production of construction materials-cast. The proposed solution in addition to the functions of melting of fly ash and prepare for their base materials with the required properties allows development in a steam boiler unit. As a result, it increases the flexibility of the cyclone furnace power boiler and therefore the entire block of steam. Through its development, it is possible during the "valley northern" off the elementary boiler burners of pulverized while maintaining it in a hot standby state by heating by combustion gases produced by combustion and gasification of coal dust in the cyclone. With this solution it is possible to significantly reduce the cost of maintaining the block steam in readiness for the production of electricity, while the processing of fly ash to economically useful materials. From the point of view of the vitrified fly ash preferred is the use of fly ash with a high loss on ignition. Produced during the vitrification of the product has a loss on ignition of less than $0.1 \%$. Through the use of suitable cooling process of molten slag, it is possible to obtain a material of high porosity that can be used eg. the production of hollow wall.
\end{abstract}

Keywords: glazing, melting, artificial aggregates, oxy-combustion, pulverized coal-fired boiler

DOI: $10.7862 / \mathrm{rb} .2016 .239$

Przestano do redakcji: $30.06 .2016 r$.

Przyjęto do druku: 30.11.2016 r. 